\title{
Quality Assessment in Surgery- Conceptual Framework
}

\author{
AAM CHOWDHURY ${ }^{\mathrm{a}}$, MM HUSSAIN ${ }^{\mathrm{b}}$
}

\begin{abstract}
Summary:
'Quality' is a popular demand in health care. Surgeons as professionals are consistently putting their efforts to meet this demand. The standard and dimensions of 'quality' are changing and expectations are rising along with social reforms driven by scientific and economic growth. On the other hand, objective assessment of care in surgical patients is difficult and dependent on factors that are not precisely related to surgical skills. It is rather performance of all in the organization and sum of each and every human and system effort. In this effort we will discuss factors related to
\end{abstract}

Introduction:

The term 'quality' is a commonly used issue in health care for long time. Quality health care and quality surgical care is synonymous-being applicable to surgical patients. Both take similar pathway. Measuring the quality of surgical care is essential to identify areas of weakness or deficiency in performance in the delivery of effective surgical care and to improve surgical outcomes. The quality in surgical patient care is actually difficult to define. It derived from Latin word 'qualitus' which signifies characteristic or merit and is a neutral term. In Oxford dictionary, "quality' is defined as, the standard of something when it is compared to things like it. That means quality is a comparative term and to compare, there should be something called 'standard'. That is the part difficult to define in health care because standard of care is a dynamic term in patient care and could vary depending on places and situation. Lee and Jones described it as, almost anything anyone wishes it to be, although it is, ordinarily, a reflection of values and goals, centered on the existing medical care system and in the larger society of which it is a part. The criteria of quality are value judgments that are applied to several

a. Dr. Abdullah Al Mamun Chowdhury, Junior Consultant, Surgery, Rangamati General Hospital, Rangamati.

b. Prof. Dr. Md. Margub Hussain, Retired Professor of Surgery, $\mathrm{DMC} \& \mathrm{H}$

Address of Correspondence: Dr Abdullah Al Mamun Chowdhury, E-mail: aamc235@gmail.com, Mobile: 01716566299

Received: 29 May 2019

Accepted: 27 January 2020 surgical care quality and different methods of assessment and their limitations.

For quality surgical care, good intent, enabling environment with organized supportive system is required with skilled surgical team and meticulous monitoring system along the care process.

Key words: Quality assessment $(Q A)$, surgery, evaluation, medical audit (MA).

(J Bangladesh Coll Phys Surg 2020; 38: 93-97)

DOI: https://doi.org/10.3329/jbcps.v38i2.45634

aspects, properties, ingredients or dimensions of a process called medical care ${ }^{1}$. JACHO (Joint Commission on Accreditation of health Care Organizations) defined quality of care as "the degree to which health services for individuals and populations increase the likelihood of desired health outcomes and are consistent with current professional knowledge".

Measuring quality in surgical practice: different approaches:

To justify quality as yardstick of patient care in surgical practice, it should be measurable. Otherwise it will not be possible to evaluate performance of care giver. There are other reasons for assessment of performance. First, patients should have information about the outcomes (expected and unexpected). Second, the stakeholders of surgical services are interested in knowing the content, quality and price of the care provided. Third, quality measurement and development will ultimately improve the care given. Fourth, it will emphasize the importance of the performance. Finally, good quality of health care is considered to be the right of patient and responsibility of care giving system.

Measurement of quality here is not easy from practical aspect. In many literatures in past, outcome was described as the measure of quality of surgical care e.g. mortality rate $^{2}$. Outcome as a measure of quality has some advantages. Outcome is observable to everyone and can be easily described and studied. For many years, outcome of care is the topic of quality related research. 


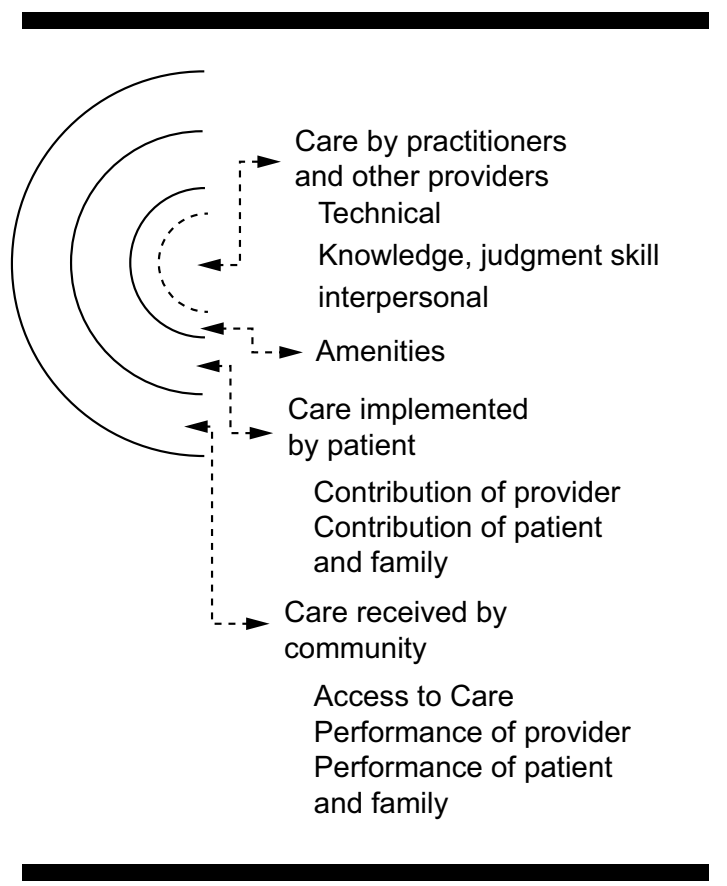

Fig.-1: Level at which quality may be assessed (Ref: Donobedian A. The quality of care: how can it be assessed? JAMA, 1988; 260(12), 1743-1748.)

But there are some limitations to take outcome as a measurement of quality. Outcomes reflect the potentiality of medical science to achieve certain results under any given set of conditions and may not be relevant for some situations. Sometimes a particular outcome may be irrelevant, as when survival is chosen as a criterion of success in a situation which is not fatal but is likely to produce suboptimal health or crippling conditions ${ }^{3}$. On the other hand, in some cases long periods of time elapse before relevant outcomes are manifested and the results are not available when they are needed for appraisal. Also success measurement in managing a poorly known clinical condition is ineffective. For this reason, comparative studies of outcome, under controlled situations, must be used. Some outcomes are generally unmistakable and easy to measure (death, for example) other outcomes, not so clearly defined, can be difficult to measure e.g. patient attitudes and satisfactions, social restoration and physical disability and rehabilitation ${ }^{4}$. The debate about disease free survival, pain free survival, recurrence free survival, overall survival versus return to work and survival is difficult to conclude. Same outcome to two different people may reflect different measure of quality. Example was given by McDermott et al. was that fixation of congenitally dislocated hip was a good practice for white people but not for Navajo Indians as they spend more time on horse saddle, it can prove as crippling ${ }^{5}$. Finally, outcome may be the summery of total patient care but it cannot give an insight into the laps and power to which the outcome may be attributed. Still outcomes, by and large, remain the ultimate validators of the effectiveness and quality of medical care . $^{6}$

A different approach to measure quality may be examining the process of care itself rather than its outcome. It is prioritizing good patient care over getting good results. Judgments are based on considerations such as the appropriateness and completeness of information obtained through clinical history, physical examination and diagnostic tests, justification of diagnosis and therapy, properly taken informed consent, technical competence in the performance of diagnostic and therapeutic procedures, including surgery, steps of an operation followed from standard protocol, evidence based practice in patient selection, operation and postoperative care, collaboration with relevant faculties where needed, evidence of preventive management in health and illness, coordination and continuity of care, acceptability of care to the recipient and so on. This approach requires a great deal of attention to specify the relevant dimensions, values and standards to be used in assessment ${ }^{6}$.

A third approach is to assess the technical and logistic part of care. This means the assessment of structure, although it may include administrative and related processes that support and direct the provision of care. The adequacy of facilities and equipment, the qualifications of medical staff and their organization, the administrative structure and operations of programs and institutions providing care, fiscal organization etc. are concern here. When there are good settings, instruments and experienced stuffs one can assume that there will be good patient care also ${ }^{7}$. But the pitfall maybe the less established relationship between structure and process which may reflect on outcome too.

\section{Combined consideration of structure, process, and outcome:}

Considering all those facts and findings Donabedian et al. ${ }^{8}$ approached to measure quality of patient care considering all three aspects i.e. structure, process and 


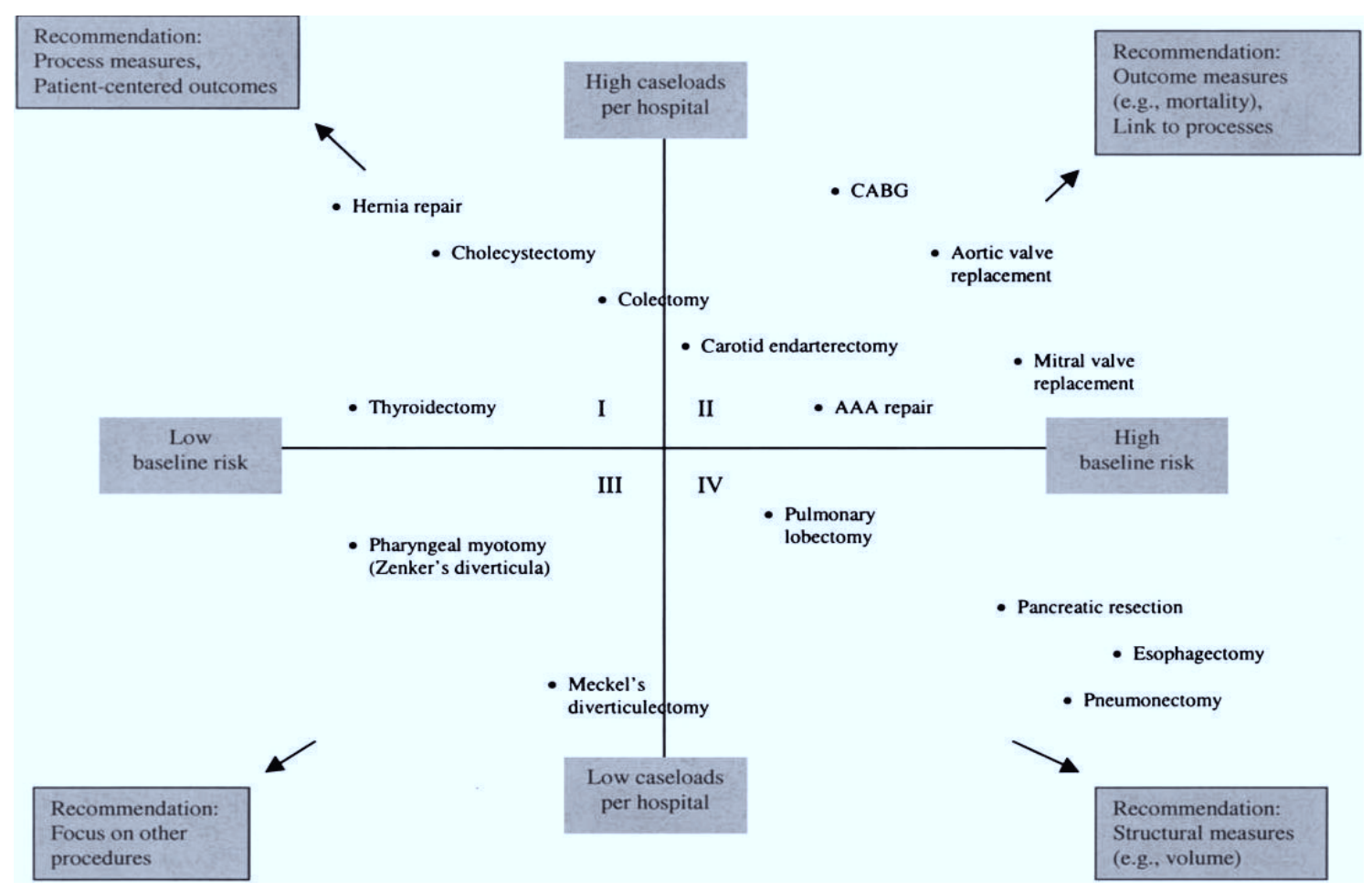

Fig.-2: Recommendations for when to focus on structure, process, or outcomes

(Ref: Birkmeyer JD, Dimick JB, Birkmeyer NJ. Measuring the quality of surgical care: structure, process, or outcomes? JAm Coll Surg. 2004; 198:626-632.)

outcome. "Structure" includes (a) attributes of material resources e.g. facilities, equipments and financial structure (b) human resources e.g. number, qualification, experience of personnel (c) organizational structure e.g. staff organogram, practice of peer review, methods of reimbursement etc. "Process" includes patient's activities in seeking care as well as practitioner's activities in making diagnosis and implement management strategies. "Outcome" denotes the effects of care on the health of patient and population. It includes improvement of patient's knowledge, behavior; satisfactions as well as obvious visible outcomes like regain abilities, disabilities or death. The background thinking in this approach is- good structure leads towards good process and good process towards good outcome. Thus measuring quality is more an administrative tool to measure and monitor performance rather than a simple clinical or technological term.

\section{Clinical indicators and quality assessment:}

$\mathrm{JACHO}^{9}$ described clinical indicator as "a valid and reliable quantitative process or outcome measure related to one or more dimensions of performance such as effectiveness and appropriateness and a statistical value that provides an indication of the condition or direction over time of an organization's performance of a specified outcome" Indicators are of two general types, sentinel event and rate-based, and can address structure, process or outcome of patient care.

Assessing quality of care for surgical patient is particularly more complex. Surgery is never a sole unite to provide care. Many other personnel and processes are related with surgical care system. Safe anesthesia, blood transfusion, preoperative evaluation by different specialists, critical care personnel, pathologist, radiologist, microbiologist, physiotherapist everyone with all their structures and process are closely related with surgical care system. That's why measuring surgical care quality in a holistic way is more difficult. A single indicator could not summarize the overall quality of care delivered ${ }^{10}$. McGory ML et al ${ }^{11}$. categorized valid quality indicators for elderly surgical patients into 8 domains i.e. co morbidity assessment, elderly issues, medication 
use, patient-provider discussions, intraoperative care, postoperative management, discharge planning, and ambulatory surgery. Bergman et $\mathrm{al}^{12}$ described ten process based quality indicators in their study i.e. prophylactic antibiotic, postoperative euglycaemia, prophylactic VTE therapy, central venous line, urinary catheter, postoperative ambulation, medication list, pressure ulcer risk assessment, oral intake documentation and surgical safety checklist. Procedure volume, re-admission and mortality rate after surgery are well known measures of hospital surgical quality ${ }^{13}$.

\section{Ensuring quality surgical care:}

Kartz and Green ${ }^{14}$ described the steps of monitoring and evaluation towards quality development for nursing care which may be applicable for surgical care also. The steps are: (1) assign responsibility, (2) delineate scope of care, (3) identify important aspects of care, (4) identify indicators, (5) establish a threshold, (6) collect data, (7) evaluate care when indicated by threshold, (8) take action, (9) assess the outcome of action and (10) communicate with those responsible for the quality assurance program. $\mathrm{JACHO}^{15}$ discussed important aspects of care under six categories. They are: (a) high volume (aspects of care which occur frequently or affect a large number of patients), (b) high risk (aspects of care which involve risks), (c) high problem areas (aspects of care which tend to produce problems for patients and staff) and (d) high cost (aspects of care which generate costs) (e) high priority and (f) of significant potential to lead to improvement in health care

At the center of quality assessment 'data' is the role player. Without authentic hospital and patient information there is nothing to assess actually. Shukri F. Khuri ${ }^{16}$ told in his Thomas B Farguson lecture "we will never be able to measure reliably the quality of surgical care, or advocate effectively for our profession and against adverse healthcare policies without the common denominator - the thread that weaves through them all: 'reliable data'. Reliable data are medicine's new weapon. Unreliable data are a weapon that has and continues to hurt us immeasurably as surgeons and healthcare professionals". Next thing is cost. In USA, participation in NSQIP (National Surgical Quality Improvement Program) costs $\$ 40$ per operation. Patient or tax payer citizens will be the ultimate payee for this cost. We must adjust cost-data fact according to our social and financial perspective.
Clifford Ko described five steps toward improving quality in surgical care. These were: (1) use good data (i.e. accurate, believable, actionable and must reflect what is actual), (2) increase evidence-based practice (finding, evaluating and implementing the best evidence), (3) spot-on policy (start implementing policies in small setting rather waiting for national guideline and quality report), (4) equi-finality ("all roads lead to Rome" situation) and be flexible and open minded), (5) implementation of quality improvement measures here and now. So, good quality can be achievedas long as there is an open mind, flexibility, and an awareness that quality implementation depends on the context where it is supposed to take place. Also of equal importance is paying attention to culture, to communication, and previous experiences. Last but not least, good quality is always cost-effective ${ }^{17}$.

\section{Quality monitoring tools:}

Patients are the focal point of surgical care. Quality surgical care is a dynamic term which changes its face time to time with the changing socio-economic perspective. Expectations of outcome and recovery are also rising with technological advances. In simple terms, quality in surgical patient care means that the right operation is chosen, everything goes well during and after surgery, and that the desired aim is achieved.

Epidemiologic studies of risk factors and the subsequent successful trials of certain strategies for risk-factor modification, has been that the clinician's key focus ought to be on reducing risk and complications below specific levels. Many checklists and software are available as quality monitoring tool. The success story of introducing WHO patient safety check-list is a good example of quality and safety initiative. Such check-list can cut surgical mortality and morbidity almost to half ${ }^{18}$.SURPASS comprehensive checklist covers stages of care in the surgical pathway (preoperative, operative, recovery or intensive care, postoperative) and is multidisciplinary which shows significant improvement in surgical outcome ${ }^{19}$. But only checklist is never sufficient. Valid and reliable instruments for assessing health-related quality of life are widely available ${ }^{20}$. Difficult task is finding ways to collect such data efficiently and inexpensively. Quality in health care can be described as "doing the right things right" 21 . A full accounting of surgical quality will require measures of appropriateness and how well patient preferences are 
incorporated in clinical decisions, in addition to those assessing how well they do after surgery.

\section{Conclusion:}

Perspective of surgical quality assessment and taking measures time to time in Bangladesh is more challenging in practical situation. We must have a developed and organized data collection system, dedicated personnel for data collection and management, dependable and secured record keeping department, more persuasion for research work and continued pressure from policy makers and societies for quality improvement. Change is a must and it should be started from now. Simple initiatives in small sectors can start quality assessment as well as improvement. Keeping records dedicated for audit, properly documented informed consent and discussion with the patient about treatment options, precise operation notes, video records of key steps of operative procedures, recording post-operative complications and outcomes, use WHO surgical safety check list, follow up of patients and audit the process every year are achievable. The process should be evidence based, reviewed periodically and can be shared among institutions as good practice. This will lead to the concept of 'high value hospital' where quality surgical care will be observed at a low $\cos \mathrm{t}^{22}$. Surgeons must take the initiative and leading role and seek collaboration of others linked to the process of patient care.

\section{Confluct of interest: Non declared.}

\section{References:}

1. Lee RI, Jones LW. The Fundamentals of Good Medical Care. Chicago: University of Chicago Press; 1933.

2. Lipworth L, Lee JAH, Morris JN. Case Fatality in Teaching and Nonteaching Hospitals, 1956-1959. MedicalCare. April-June, 1963; 1:71-76.

3. Lembcke PA. Medical Auditing by Scientific Methods. JAMA. October 13, 1956; 162:646-655.

4. Kelman HR, Willner A. Problems in Measurement and Evaluation of Rehabilitation. Arch of Phys Med and Rehab. April 1962; 43:172-181.

5. McDermott $\mathrm{W}$ et al. Introducing Modern Medicine in a Navajo Community. Science (January 22 and 29)1960; 131:197-205, 280-287.

6. Donabedian A. Evaluating the quality of medical care. Milbank Memorial Fund Q 1966; 44:166-206.
7. Goldmann F, Graham EA. The Quality of Medical Care Provided at the Labor Health Institute, St. Louis, Missouri. St. Louis:The Labor Health Institute; 1954.

8. Donobedian A. The quality of care: how can it be assessed? JAMA, 1988; 260(12): 1743-1748.

9. Joint Commission (JCAHO). The measurement mandate: On the roads to performance improvement in health care. Joint Commission on Accreditation on Health Care Organizations, Illinois; 1993.

10. Main DS, Cavender TA, Nowels CT, Henderson WG, Fink AS, Khuri SF. Relationship of processes and structures of care in general surgery to postoperative outcomes: a qualitative analysis. J Am Coll Surg 2007; 204:1147-56.

11. McGory ML, Kao KK, Shekelle PG, Rubenstein LZ, Leonardi MJ, Parikh JA, et al. Developing quality indicators for elderly surgical patients. Ann Surg 2009; 250:338-47.

12. Bergman $S$, Deban M, Martelli $V$ et al. Association between quality of care and complications after abdominal surgery. Surgery. 2014;156: 632-639 .

13. Tsai TC, Joynt EK, Orav EJ, Gawande AA, Jha AK. Variation in surgical-readmission rate and quality of hospital care. N Engl J Med 2013; 369:1134-42.

14. Katz J, Green E. Managing quality: A guide to monitoring and evaluating nursing services. Mosby Year Book, St Louis; 1992.

15. Joint Commission on Accreditation on Health Care Organizations (JCAHO). 2001. Glossary of terms, call for performance measures. Online, www.jcaho.org/perfmeas/ coremeas/cm_gloss.html.

16. Khuri SF. Quality, advocacy, healthcare policy, and the surgeon. Ann Thor Surg 2002; 74:641-649.

17. Riss $P$, Aigmueller T. Five steps toward improving quality in surgical care. Int Urogynecol J2014; 25:855-856

18. Haynes AB, Weiser TG, Berry WR, et al. A surgical safety checklist to reduce morbidity and mortality in a global population. N Engl J Med 2009;360:491-9.

19. De Vries EN, Prins HA, Crolla RMPH, Outer AJD, Andel $\mathrm{GV}$, et al. Effect of a comprehensive surgical safety system on patient outcomes. N Engl J Med 2010; 363:1928-37.

20. McDowell I, Newell C. Measuring health: a guide to rating scales and questionnaires. New York: Oxford University Press; 1996.

21. Birkmeyer JD, Dimick JB, Birkmeyer NJ. Measuring the quality of surgical care: structure, process, or outcomes? J Am Coll Surg 2004;198:626-32.

22. Espinoza GR, Espinoza GJP. Quality in surgery: towards a better understanding of surgical complications. Rev Med Chil 2016 Jun; 144(6):752-7. 